\title{
An Investigation into the Implementation of a Total Quality Management System to Improve Operational Performance at a Fleet Management Company within a Government Organisation
}

\author{
Mr Neeren Juganath, Mrs Nellie Naranjee
}

\begin{abstract}
With the evolution of the business world all stakeholders have become more prone to ensuring that they do receive the best product or service for their financial sacrifice. The mitigation of the traditional approach to facilitating business has seen the rise of the new era, today commonly known as "Total Quality Management" (TQM), which has for a lengthy period being effectively adjudicated in the manufacturing and production concern and has recently seen rise to the service related industry. The initiative circumnavigating the intention behind this study was to ensure effective resource utilisation with optimum output in order to facilitate an investigation into the implementation of a total quality management system to improve operational performance at a fleet management company within a government organisation. The study was geographically aligned to a local municipality within Kwazulu Natal.
\end{abstract}

Keywords: Fleet Management, Quality, Total Quality Management, Operational, Performance

Abbreviations: CRM-Customer Relationship Management, CSF- Critical Success Factors, HR-Human Resource, SPSS- Statistical Package of Social Sciences Software, ISO- Statistical Process Control, SRMSupplier Relationship Management, TQM- Total Quality Management, TQMS-Total Quality Management System, JiT- Just in Time

\section{INTRODUCTION}

Increased competition, customer needs and expectations drive the philosophy of Total Quality Management (TQM). Heizer and Render (2011:222) state that TQM is the collaboration of characteristics and features of a service or product that bears on its ability to meet and satisfy the overall implied and stated needs.

The overall result of aligning quality to management is pivotally focused on increasing output with minimal input and the elimination of wasteful practices. Singh, Grover and Kumar (2008:162) illustrate that organisations strive to satisfy the tangible and intangible needs of their stakeholders and are focally dependant on TQM which is a description of culture and attitude. In pursuit of doing things right the first time round and despite TQM being initially developed for the manufacturing industry, it is vastly being accepted in the service and public sector and is now becoming as a generic management tool. This study highlights the investigation into the implementation of a Total Quality Management System (TQMS) to improve operational performance at a fleet management company within a government organisation and it also proposes potential solutions based on the research literature and findings.

eFleet is a public organisation that services and satisfies the mobility needs of other functional departments within a local Municipal Metropolitan Region in Kwa-Zulu Natal. The organisation has recently changed the way they do business from the traditional approach to that of data abundance. Their strategy is to focus on a sheer variety of information available on data warehousing and other related data sources.

Some changes have proved effective whilst new challenges have emerged due to increased reliance upon networked data. One serious problem that needs to be addressed is that of inaccurate data that still poses a threat. The activities associated with the quality of data involve in-depth analysis, quality reports and presentations to senior officials. Saltsgiver (2004:1) confirms that one of the major life bloods of eFleet is that of accurate mileage reporting. Mileage data has to be incorporated into every report and any inaccuracy of such data will skew the end reports. A typical scenario would be where excessive mileage is recorded, it will reflect as the vehicle is performing exceptionally below the 
benchmarks and where there is reduced or zero mileage reported, it would throw this vehicle out as an exception of over / under performing. This could also result in billing purposes where excessive mileage would deduce high costs and reduced / zero mileage depicting zero costs.

eFleet is a public enterprise that is responsible for the mobility of its stake holders including all variable and fixed costs associated with the operation of the entity. The issue arises from the output reporting areas where analytical results have been misrepresented in the form of data driven systems with human intervention as well. The grey areas in this dilemma are that of management's drive as well as policies and procedures.

\subsection{Statement of the Problem}

eFleet requires reports, dashboards and presentations to line management on a daily, weekly, monthly and quarterly basis. These reports have huge exceptions and variances due to lack of potential knowledge of staff on the input fields. The content of the report outputs are distorted due the lack of expertise in the field, teamwork and instilled discipline. Further to state that there is a lack of effective communication both upstream and downstream with an impact on customer relationship management as well as supplier relationship management. As an organisation that is responsible for transportation needs, poor quality of reports affect decision making, presentations and management information dashboards thus resulting in poor strategic decisions. The desired result is to improve efficiencies, improve turn around strategies in terms of asset replacements, education and training, mentoring, language barriers, poor human resource practices, organisational culture, leadership and benchmarking. Customer dissatisfaction evidently reflects that eFleet is faced with an ineffective quality management system.

\subsection{Aims and Objectives of Study}

The aim of the study is an investigation into the implementation of a Total Quality Management System to improve operational performance at a fleet management company within a government organisation. The strategy is to steer towards a more streamlined and error free Total quality management System to ensure pivotal success.

The objectives of this include the following;

- To identify the challenges that affect operational performance at eFleet

- To identify the factors that hinders the successful implementation of total quality management at eFleet.

- To provide recommendations on improving factors influencing successful implementation of total quality management at eFleet.

This study contributes to the relationship between TQM and the change parameters within an organisation, inculcating the culture of expertise, experience and knowledge sharing. From a business perspective, this study may improve the profitability of eFleet not limited to the efficiencies and confidence of end users, both in the public and private sectors of service related organisations. The study may also contribute significantly to the growing body of knowledge to TQM implementation, execution and evaluation both in the public and private sectors, within the academic sphere. The findings of this study may be applicable to all service related organisations and improve market share with the intent to maximise profits and beyond, notwithstanding the clarification and need for TQM as a strategy.

\subsection{Review of Literature}

This section circumnavigates the current practices and policies that illustrate the fundamental principles with regards to the chosen research topic. An overview is provided about the theoretical basis of TQM, as well as its importance to the survival of any organisation, with specific reference to public and private sector service related organisations.

\subsection{Definition of TQM}

Zink (2007:394) illustrates that TQM defines an organisation's culture and supports the constant attainment of customer satisfaction through an integrated system of tools, techniques and training. The definition of TQM varies depending on the author and the related industry perspective from which it is defined. According to Dahlgaard and Dahlgaard-Park (2006:266), TQM is a company culture 
characterised by increased customer satisfaction via continuous improvements, within which all employees are actively involved.

\subsubsection{The Basic Principles of TQM}

Thamizhmanii and Hasan (2010:204) state that the on-going process of business process improvement with regards to supplier satisfaction and customer satisfaction is the basic philosophical principal of TQM, which further illustrates the scope of TQM below:

\subsubsection{Total Customer Satisfaction}

The customer is a primary stakeholder that wants their money's worth for either a product or service received (Tasar and Celik, 2011:33).

\subsubsection{Philosophy of the Organisation}

Tasar and Celik (2011:33) state that they go the extra mile and portray a sense of appreciation and belonging in order to provide premium service and quality to their customers to ensure repeat business and customer retention strategies.

\subsubsection{Users}

Customer satisfaction must be enforced to both stakeholders (user and customer) even if the user is different from the purchaser (Tasar and Celik, 2011:33).

- Internal Customers - This is confined to consecutive line departments within the organisation to satisfy the quality of the product / service that is provided to the end product along the process flow of the production / service line (Tasar and Celik, 2011:33).

- Chain of Customer - There is usually a chain of customers before the end product reaches the ultimate customer thus the quality of the product / service must be facilitated in a manner that it satisfies the needs of this ultimate customer (Tasar and Celik, 2011:33).

\subsubsection{Supplier Satisfaction}

This is the second principle to satisfy the supplier from whom one is purchasing either services or goods (Schiele, Calvi and Gibbert, 2012:1178).

- External Suppliers - Schiele et al. (2012:1178) highlights that the organisation needs to initiate clear instructions to the suppliers with regards to the requirements of services or goods expected, so as to ensure that quality received from external suppliers will ensure quality provided to external customers.

- Internal Customers -It is the requirement of the line supervisor to ensure that his subordinates are productive and happy and that they have the necessary instructions and tools to complete the tasks set out for them including rewards of praise and good pay (Schiele et al., 2012:1178).

- Job Improvement (Employee performance) - This is to influence productivity and to retain a good work force and ultimately to satisfy his / her internal customers (Gul, Jafery, Rafiq and Naeem, 2012:19).

- Empowering the Workforce - Parumasur and Govender (2009:01) state that this process empowers the internal suppliers and also influences them to make better decisions and to give of their best.

\subsubsection{Continuous Improvement}

This is the third principle and is an on-going process to keep abreast of the pack as strategies are always improving and also to remain competitive within the market arena (Tasar and Celik, 2011:33).

- Work Smarter not Harder - Improvements using a form of analysis of where the bottlenecks, delays and resistance are is what is needed (Tasar and Celik, 2011:33).

- Worker Suggestions - The workforce have the ears to the ground and often highlight ways to eliminate downtime, waste and ultimately improve processes which often acts as a source of continuous improvement (Tasar and Celik, 2011:33).

- Quality Methods - Poke a yoke, Just in Time (JiT) and variability are just some of the quality methods that can assist in reducing waste and improving processes (Tasar and Celik, 2011:33). 


\subsection{Barriers that Hinder the Successful Execution of TQM}

It is the change management process that hinders or acts as a barrier towards promoting strategic quality assurances / alliances that would serve as a sustainable measure towards organisations in the competitive market arena. Heizer and Render (2011:222) state that in order for TQM to be introduced and sustained one would need to understand the fundamentals of those barriers before and after implementation.

\subsubsection{Barriers to TQM Implementation}

Charantimath (2011:76) relates to some of the most common barriers that are faced during the implementation process:

\subsubsection{Lack of Top Management Commitment}

According to Talib, Rahman and Qureshi (2011:563), this is one of the leasing stumbling blocks when implementing TQM successfully in an organisation. There is a lack of visibility of top management's participation in the implementation of quality improvement programs and was further hindered by the lack of encouragement of employee involvement.

\subsubsection{Poor Vision and Plan Statement}

Talib et al. (2011:563) illustrate that the successful implementation of TQM requires detailed planning as there is no clear long term vision (strategy). The implementation of TQM may lead to failure if there is a weak vision and plan statement limited to annual business performance plans and product quality goals.

\subsubsection{The Government Influence (Lack of Effective Measurement of Quality)}

Discussions by Oruma, Mironga and Muma (2014:332) highlight that the bureaucracy of government has proved to be one of the most influential barriers to the successful implementation of TQM which adjudicates the complicated procedures thus reducing the customer responses to implement quality tools and techniques. Government does not have a national quality policy thus negatively impacting the effect of TQM implementation.

\subsection{Factors that may Influence the Successful Implementation of TQM}

Long (2013:01) advocates that these factors have been well thought out and will ensure pivotal success during the TQM implementation process.

\subsubsection{Total Quality Management}

Increased competition, customer needs and expectations drive the philosophy of Total Quality Management. Heizer and Render (2011:222) state that TQM is the collaboration of characteristics and features of a service or product that bears on its ability to meet and satisfy the overall implied and stated needs.

\subsubsection{Resistance to Change}

Human nature is a fact of resistance to change. McKinnon (2013:56) states that the way things were done in the past tends to be met with resistance to change, refer below:

- Change adjudicates business advancement and improvement

- The masses may be subjected to anxiety to change but will inspire the rest that understand the advantages of the change requested

- Anxiety to change is prompted by resistance

- Resistance can halt and wreck any change ideas for business advancement and improvement

Wankhade and Dabade (2010:69) state that this may not always be the case; an example of such is an increase in income would greatly facilitate a positive attitude and consequently resistance is encountered when there is continued uncertainty around the change.

\subsubsection{Change and Reinvent}

Brown (2011:164) states that organisations are being forced to drastically change and reinvent processes in order to overcome economic pressures and increased competition. The challenge comes when change management is ineffective. Adaptation has to be rapid in order to sustain business. 
People are the core focus of the greatest challenges that sparks significant problems and challenges, especially in times of a large scale change that involves sub departments and individuals.

Brown (2011:164) explains that personal change involves an amendment to the following;

- Behavioural patterns

- Relationships that have been defined

- Job skills

Brown (2011:164) states that organisational change indicate that the following will be altered;

- Policies

- Work flows

- Organisational structures

- Procedures

- Manufacturing processes

Continuous improvement and problem solving techniques is what TQM adjudicates, further catering for maximum return on investment (ROI). The religious adoption of the TQM philosophy will help organisations achieve business excellence to further enhance human capacities and capabilities which would be conducive to the optimal utilisation of the resources, improved processes and the culture of the organisation. New business environment, will be innovative with a clear focus of managing and defining the customer side and process emphasis through management knowledge and TQM principles. TQM innovation steered towards a quality based strategic management philosophy will be testament to this new environment. The TQM strategy will assist in achieving business excellence and gaining competitive advantage.

\section{MeThodology}

This section will facilitate the elaboration and justification of the research design and methodology utilised for this research study.

\subsection{Rationale for Methodology}

Grinnell, Krysik and Unran (2005:291) define research methodology as the use of quantitative and qualitative approaches to solve specific problems or to make informed decisions. The objective of the study adjudicated the type of research methodology that was adopted for the meaningful purpose of this study. An investigation into the implementation of a TQMS to improve operational performance was the primary and underlying objective of the study with an influence to understand the areas that would eliminate the bias and overcome the true pivotal potential to the success of TQM for improved operational performance.

\subsection{Research Design}

Saunders, Lewis and Thornhill (2007:131) state that the guide that is utilised for collecting and analysing data (to understand a phenomenon) is administered by the research design which serves as a framework or plan for the study in order to deduce meaningful recommendations and conclusions. The quantitative experimental research approach was used in this study as it facilitated for the adjudication of a researcher that focally expedited a study on a group of individuals within an organisation.

\subsection{The Research Philosophy}

Williams (2011:01) explains that research philosophy is an integral and pivotal part to research methodology in order to ensure that data is effectively and appropriately retrieved, further to state that the set of shared assumptions, practices, concepts and values is a perspective that is based on research paradigm. The function of the researcher and the nature of the world are collated in order to facilitate a more effective study. 


\subsection{Target Population}

According to Saunders, Lewis and Thornhill (2009:212), the full set of cases from which the sample is taken is called the population. The total staff complement at eFleet is 263 of which the researcher has selected 105 participants (40\% of the population) to gather primary data. Questionnaires were issued to internal and external stakeholders of eFleet in order to determine the impact of TQMwithin the organisation.

\subsection{Sampling}

Data needs to be collated in order to answer the research objectives and questions. Rubin and Babbie (2009:131) state that there are two types of sampling methods known as probability and nonprobability. Random sampling, stratified sampling and systematic sampling are the various methods that are utilised in probability sampling where each member of the population has a non-zero probability of being selected.

Rubin and Babbie (2009:131) illustrate that the sampling error can be calculated in probability sampling and this serves as an advantage to that of a non-probability, thus the probability random sampling method was used in this study.

\subsection{Sample}

A subset of the population is what makes up a sample and compromises of members selected from the population. Sekaran (2003:266) states that a subject is a single member of the sample, just as an element is a single member of the population; therefore a sample is formed by some and not all elements of the population.

\subsection{The Sample Size}

Siegel (2011:601) illustrates that a representative sample is selected from the study population due to the fact that it is not always practical or possible to include the entire study population in the research study. Rubin and Babbie (2011:338) define a sample as a segment of the population that is selected for research and that sampling will provide a valid alternative to a census survey. This study was concluded with a $100 \%$ response rate

\subsection{Research Instrument}

The instrument that was utilised in this study for gathering quantitative data was a questionnaire. The structure of the questionnaire was aligned to the objectives of the study so as to determine the true and unbiased reflection of the study in its entirety. Althanasiou, Debas and Darzi (2010:487) illustrate the advantages and disadvantages of questionnaires below.

\subsection{Advantages of Questionnaires}

- Cheap and quick to administer

- Cost effective compared to interviews

- Simple and quick for candidates to complete

\subsection{Disadvantages of Questionnaires}

- Candidate may feel that they will be prejudiced, penalised or biased and may not be willing to part take in the completion of the questionnaire.

- Questionnaires cannot deter later questions from being answered first and the initial questions last, which could deter / skew the responses on the questionnaires.

- They may not be fully completed which could be a result of language barriers or literacy levels.

\subsection{Pilot Study}

Brink, Van der Walt and Van Rensburg (2006:166) maintain that the purpose of a pilot study is to detect possible flaws in the data-collection instruments. Ten participants from the study population had facilitated the successful outcome of the pilot study which necessitated minor amendments to the layout and structure of the questionnaire based on feedback received from the participants. 


\subsection{Administration of the Questionnaires}

The administration and collection of the questionnaires was facilitated by the researcher. The researcher attended operational meetings that were facilitated weekly by key strategic role players within the organisation. The purpose of the study was highlighted to all, defining the purpose and intent, circumnavigating the study including that of confidentiality and anonymity. The researcher allocated a 20 minute time limit to complete the questionnaire prior to participants exiting the room so as to minimise or mitigate any form of coercion or bias.

\subsection{Data Analysis}

Wang (2009:1) states that in order for organisations to make informed decisions, the quality, accuracy and the timely analysis of the data is pivotal to decision making. Quantitative data consists of numerical measurements and statistical analysis of measurements with the overall outcome to determine logic and understanding. There is no single best practice as this would require a creative, disciplined and systematic approach.

\section{Descriptive Statistics}

The data analysis was facilitated with the support of a professional statistician. The descriptive analysis and tests were performed which incorporated the collaboration of frequency tables with counts and graphs with percentages which emanated from the outcome of the analysis. The data was analysed by the researcher with the assistance and guidance of a professional statistician. As this was a quantitative study, the data analysis was facilitated using Statistical Package for Social Sciences Software (SPSS). The non-parametric correlations (spearman's Rho), and Kruskal-Wallis (nonparametric equivalent for ANOVA) was used.

\subsection{Validity and Reliability}

Validity

Validity refers to the degree at which an instrument is doing what it is intended to do and evidence of validity is provided by several sources. Validity and reliability are further correlated to the data retrieval methods and the tools used to facilitate in the research study and the extent at which the researcher has been able to limit any bias in the data retrieval process. Moule and Goodman (2009:184) illustrate that credibility is awarded to the research instrument and research findings.

\section{Reliability}

Reliable research results are attributed to the mitigation of participation error, observer error, observer bias and participant bias, which are facilitated using the adjudication of researcher confidence in ensuring that all factors and objectives are duly considered throughout the study. Moule and Goodman (2009:186) further elaborate that reliability refers to the consistency and stability of a measurement and is concerned with whether the results of the study are replicable in any way whatsoever. The results after carefully analysing the data from the questionnaires proved that the questions had indeed measured the intended variables. A Cronbach's Alpha analysis was performed to verify the reliability of measures and all questions scored 0.7 thus indicating a good reliable co-efficient.

\subsection{Limitations of the Study}

Limitations and delimitations are contained in any study. Brutus, Aguinis and Wassmer (2013:48) confirm that the definition to the limitations of the study are those characteristics of design or methodology that impact or influence the interpretation of the findings of research, to which the researcher has no control over further to state that the delimitations are imposed restrictions put into effect by the researcher.

a) The following limitations were identified:

- Not all members could be surveyed due to the large numbers in the target population.

- The quantitative research methodology does not cater for further investigations into participant responses.

- Further elaboration of answers could not be catered for from closed ended questions. 
b) The following delimitations were imposed:

- Time was of the essence with regards to the completion of questionnaires thus the construction of close ended questionnaires with multiple choice type answers.

- Short concise questionnaires to grasp the respondent's attention detailing a limited number of questions which were all correlated to the research objectives.

\subsection{Elimination of Bias}

Bias can be defined as the tendency to prevent unprejudiced consideration of a question in research (Pannucci and Wilkins, 2010:619). Conclusive evidence to any research could be influenced and subjected to bias.

The following steps were imposed throughout the study to adjudicate the research objectives:

- There was zero discrimination to all socio economic groups as all social classes were at liberty to part take in the study.

- All ethnic groups and race groups participated in the study with no mention or distinction between either or groups.

- The study was facilitated by bother genders with selective reference to wording regarding gender.

\subsection{Ethical Considerations}

The data collation stage was adjudicated by a range of ethical considerations that the researcher had to abide by and this is further elaborated on in this chapter.

\section{Informed Consent}

Blumberg, Cooper and Schindler (2005:95) state that the researcher is obliged to stick to the information and procedures outlined after having obtained the consent of the respondent. A covering letter was attached to the questionnaire informing the participants on the reasons for the study and that they were at liberty to complete the questionnaire at their own free will, the participants had to provide their own informed consent either verbally or via email prior to completing the questionnaire.

\section{Participant Protection}

Watson, McKenna, Cowman and Keady (2008:131) state that the researcher must ensure that all participants are protected and that no harm was inflicted upon them during their role in this study. All responses received were treated with the utmost confidentiality and would not discredit or deem to be harmful to anyone in anyway whatsoever.

\section{Confidentiality and Anonymity}

The researcher facilitated the confidentiality and anonymity of all participants throughout the study by ensuring that no names or personal information was recorded in any of the data collection tools.

\section{Ethical and Organisational Approval}

Consent was obtained from eFleet management which granted formal permission to undertake the study and served as ethical clearance. Protocol was submitted to Management College of Southern Africa (Mancosa) Ethics Committee for ethical clearance and approval.

\section{Conclusion}

This chapter justified the choices made with regards to the methodology facilitated in this study. The rationale of the study as well as the research design including data collection and analysis had been further elaborated upon. All limitations to the study were highlighted inclusive of ethical considerations.

\section{DATA ANALYSIS, INTERPRETATION AND FINDINGS}

\subsection{The Research Instrument}

The research instrument consisted of 23 items, with a level of measurement at a nominal and ordinal level. Cronbach's Alpha equalled to 0.781 (section B = question 5 to question 12) and 0.772 (section $\mathrm{C}$ - question 13 to question 22), which indicates poor reliability. However upon analysis it became apparent that the low reliability is attributed to the sensitivity of the topic prompting inconsistent responses $(\alpha=0.781, \mathrm{~N}=8$ for section $\mathrm{B})$ and $(\alpha=0.772, \mathrm{~N}=10$ for section $\mathrm{C})$. 
An Investigation into the Implementation of a Total Quality Management System to Improve Operational Performance at a Fleet Management Company within a Government Organisation

\subsection{Findings and Interpretation of Results}

Section B: Challenges that Affect Operational Performance at eFleet

Reliability Statistics (Cronbach's Alpha - Section B)

Table1.0. Reliability Statistics (Cronbach's Alpha - Section B)

Reliability Statistics - Section B

\begin{tabular}{|c|c|}
\hline Cronbach's Alpha & N of Items \\
\hline $\mathbf{0 . 7 8 1}$ & $\mathbf{8}$ \\
\hline
\end{tabular}

Section B is reliable, Cronbach's Alpha is $>0.7(\alpha=0.781, \mathrm{n}=8)$

Section B of the questionnaire targeted the first objective of the study which was to identify the challenges that affect operational performance at eFleet.

\section{Kruskal-Wallis and Crosstabs}

Table1.1. Kruskal-Wallis and Crosstabs

\begin{tabular}{|c|c|c|c|c|c|c|}
\hline \multirow[t]{2}{*}{ Gender } & \multicolumn{5}{|c|}{ B2. I am satisfied with the level and accuracy of the data reports? } & \multirow[t]{2}{*}{ Total } \\
\hline & Strongly Agree & Agree & Neutral & Disagree & Strongly Disagree & \\
\hline Male & 6 & 27 & 10 & 4 & 0 & 47 \\
\hline Female & 4 & 16 & 24 & 13 & 1 & 58 \\
\hline Total & 10 & 43 & 34 & 17 & 1 & 105 \\
\hline
\end{tabular}

There is a significant difference in gender and satisfaction with the level and accuracy of the data reports $(\mathrm{H}(1)=11.869, \mathrm{p}=0.001)$. Females are more likely to disagree with this statement, whereas males were more likely to agree.

Section C: Factors that may Influence the Successful Implementation of a Quality Management System

Reliability Statistics (Cronbach's Alpha - Section C)

Table1.2. Reliability Statistics (Cronbach's Alpha - Section C)

Reliability Statistics - Section C

\begin{tabular}{|c|c|}
\hline Cronbach's Alpha & N of Items \\
\hline 0.772 & 10 \\
\hline
\end{tabular}

Section C is reliable, Cronbach's Alpha is $>0.7(\alpha=0.772, n=10)$

The second objective of the study was facilitated under Section C. Respondents were required to identify the factors that hinder the successful implementation of TQM at eFleet. The feedback options were once again presented in the form of a Likert scale with the option being; strongly agree, agree, neutral, disagree and strongly disagree.

Table1.3. Likert Scale

\begin{tabular}{|c|c|c|c|c|}
\hline Strongly Agree & Agree & Neutral & Disagree & Strongly Disagree \\
\hline
\end{tabular}

\section{RESULTS, INTERPRETATIONS, FINDINGS AND RECOMMENDATIONS}

\subsection{Introduction}

This chapter illustrates, presents and discusses the findings of the study from the literature review and the primary research. Further elaboration to the overall conclusions from the study will be highlighted. Recommendations for further strategic research interventions will also be discussed. This chapter culminates with an overall conclusion of the study.

\subsection{Findings from the Study}

The key findings from the literature review and the primary research study are discussed further in isolation of each other; titled as key findings from the literature review and key findings from the primary research.

\subsection{Key Findings from the Literature Review}

- Zink (2007:394) illustrates that TQM means that the organisation's culture is defined by and supports the constant attainment of customer satisfaction through an integrated system of tools, techniques and training. Gharakhani, Rahmati, Farrokhi and Farahmandian (2013:46) further define total quality management (TQM) as a systematic quality improvement approach for firm- 
wide management for the purpose of improving performance in terms of quality, productivity, customer satisfaction and profitability.

- Oakland (2012:13) states that statistical process control and numerous other technical methods and behaviour concepts (TQM concepts) were collaborated and termed "TQM".

- This is however in contrast to the argument of Yang (2003:10), who has noted that with TQM having being implemented for more than twenty years, academics and practitioners alike have achieved a degree of consensus on TQM.

- Thamizhmanii and Hasan (2010:204) state that the on-going process of business process improvement with regards to supplier satisfaction and customer satisfaction is the basic philosophical principal of TQM.

- Total customer satisfaction is the first principle and a must, as this is the stakeholder that wants their money's worth for either a product or service received (Tasar and Celik, 2011:33). Customer satisfaction must be enforced to both stakeholders (user and customer) even if the user is different from the purchaser (Tasar and Celik, 2011:33).

- Supplier satisfaction is the second principle to satisfy the supplier from whom one is purchasing either services or goods (Schiele, Calvi and Gibbert, 2012:1178).

- Job improvement (employee performance) is to influence productivity and to retain a good working force and ultimately to satisfy his / her internal customers (Gul et al., 2012:19).

- Parumasur and Govender (2009:01) state that by empowering the workforce it will in turn empower the internal suppliers and also influence them to make better decisions and to give of their best.

- Continuous improvement is the third principle and is an on-going process to keep abreast of the pack as strategies are always improving and also to remain competitive within the market arena (Tasar and Celik, 2011:33).

- Tanninena, Puumalainen and Sandstrom (2010:182) conducted a survey to analyse the effect and the importance of TQM in a multinational company with presence in 40 countries on five continents and then provide empirical evidence that TQM has a positive effect on profitability, productivity and customer satisfaction.

- Although the TQM philosophy has its roots in the manufacturing industry, it is based on many techniques which could easily be transferred to the service related industry (Manjunath, Metri and Ramachandran, 2007:131).

- The International Standard Organisation (ISO) 9001:2008 is currently being used in South African service sector, to develop their quality management systems and assessing their own competence.

- TQM has been introduced into the service sector post its implementation in the manufacturing sector which proved the improvements in organisational performance and could be better illustrated as a collaboration of principles, practices and techniques (Talib, 2013:05).

- The actions of the TQM model are associated with the activities that are required for the implementation of the TQM philosophy in the organisation. The inclusions towards this will collate of the following; TQM training for employees and the meaning of philosophy, involvement and participation of upper management in the implementation phase and the structural organisation change required for the change in terms of responsibilities, departments and levels of management (Al-Shobaki et al., 2010:305). This adjudicates the service sector organisations to receive feedback with regards to the level of required improvement and what needs to be done to collate and achieve desired optimum deliverables and better results (AlShobaki et al., 2010:305).

- Heizer and Render (2011:222) state that in order for TQM to be introduced and sustained one would need to understand the fundamentals of those barriers before and after implementation.

- According to Talib, Rahman and Qureshi (2011:563), the lack of top management commitment is one of the leasing stumbling blocks when implementing TQM successfully in an organisation. 
- Irfan and Kee (2013:61) illustrate the critical factors for TQM, which are namely; people and customer management, supplier partnership, customer satisfaction orientation, external interface management, communication of improvement information, strategic quality management, operational quality management, quality improvement measurement systems, teamwork structure for improvement and corporate quality culture.

- Rezaei, Celik and Baalousha (2011:742) adjudicate that a performance measurement system can be defined as a set of metrics used to quantify both the efficiency and effectiveness of actions in order to fulfil the performance objectives (primary measures) so as to meet the desired needs of the customer (secondary measures).

- Koh, Demirbag, Bayraktar, Tatoglu and Zaim (2007:103) concur with Demirbag et al. (2006:829) that by identifying and improving the impact of TQM practices thereby assisting in improving organisational performance.

- Gul et al., (2012:19) illustrate that in order to achieve customer satisfaction by providing quality products one would need to adjudicate a Total Quality Management business approach.

- Improvement and employee empowerment attains brilliance in business support with the aid of total quality management (Gul et al., 2012:20).

- Talib (2013:10) highlights that increased performance is brought about with pivotal attention being awarded to those that represent managerial and organisational operational areas.

\subsection{Findings and Conclusions from the Primary Research}

All conclusions are correlated to the findings from the primary research;

\subsection{Demographics of Respondents}

The demographic results of the research revealed the age, the gender, and the years of service at eFleet including the educational qualifications per respondent.

\subsection{Objective 1: To Identify the Challenges that Affect Operational Performance at eFleet}

- A collective response of $63.9 \%$ of the participants agreed that all systems and data related issues are effectively captured and uploaded to all systems for the effective use of report extrapolations by all internal and external users.

- The results of the primary data reveal that whilst $32.4 \%$ remained neutral and $17.2 \%$ disagree, the balance of $50.5 \%$ of the respondents have collectively agreed that satisfaction has been achieved with the level of accuracy of all data related reports for the purpose of strategic decision making at eFleet.

- The research highlighted that although majority of the respondents at $47.6 \%$ agreed that the staff compliment have adequate knowledge in the transport industry, there has been rebuked claims by $25.8 \%$ that disagreed with this statement and a further $26.7 \%$ that remained neutral in their response.

- A collective response of $55.2 \%$ agreed that communication is ineffective due to language barriers amongst staff and key stakeholders, noting that a further $30.5 \%$ remained neutral in their response to this question.

- Results of the research reveal that $46.6 \%$ of respondents agree that there are adequate HR practices in place in order to sustain that transformation, a further $32.4 \%$ remained neutral and $21 \%$ that disagreed in their response to this statement.

- Revelation of the results indicate that $55.2 \%$ of the respondents have agreed that they have the support of top management effecting change downstream, pivotal to success, albeit has to be further noted that $20 \%$ disagreed with their response to this question.

- Majority of the respondents at $94.3 \%$ have unanimously agreed that skills and training programmes should be on-going in order to sustain the upkeep of market demands and change trends. 
- Research shows that $52.4 \%$ of the respondents agreed that satisfaction has been achieved with regards to the services rendered / offered from a TQM approach; however there has been a contrasted $40 \%$ that remained neutral and a further $7.7 \%$ that highlighted their disagreement in this regard.

\subsection{Objective 2: To Identify the Factors that Hinders the Successful Implementation of TQM at} eFleet

- A collective $63.8 \%$ of the respondents agreed that eFleet's leadership is committed to the implementation of TQM, with $27.6 \%$ that remained neutral and a further $8.6 \%$ minority that disagreed.

- The adoption and communication of the benefits of TQM has been concurred with by $57.1 \%$ of the respondents whom have agreed with this statement, resulting in a further $32.4 \%$ that remained neutral in their response.

- An estimated one quarter of the respondents at $24.8 \%$ remained neutral in their response with regards to eFleet being able to facilitate their own benchmarks, however the $67.6 \%$ majority have indicated their agreement that eFleet does have the ability to facilitate their own benchmarks.

- Conclusive analysis of the primary data reveals that $44.8 \%$ of the respondents agreed that management has aligned all critical success factors (CSF) in line with the implementation of TQM; however there has been a further $35.2 \%$ that remained neutral in their response.

- The study highlights that a collective $59 \%$ of the respondents are in agreement that employee empowerment is the greatest TQM tool at eFleet, it has to be further noted that $22.9 \%$ of the respondents remained neutral in their response.

- A staggering $93.4 \%$ of the respondents have agreed that education and training is pivotal to the successful and effective implementation of TQM and it has also been further noted that the remaining $6.7 \%$ remained neutral in their response to this question.

- The collective response at $91.4 \%$ agreed that the deployment of customer relationship management (CRM) should be more closely fostered and expedited more effectively, with the remaining $8.6 \%$ that remained neutral in their response to this question.

- The results of the primary research data illustrates that $90.5 \%$ of the respondents agree that the deployment of a more effective and closer supplier relationship management (SRM) should be expedited, it needs to be further noted that the remaining $9.5 \%$ of the respondents remained neutral in their response to this question.

- Majority of the respondents at $92.4 \%$ have agreed that in order for the implementation of TQM to be successful at eFleet one would need to adopt, accept, adhere and communicate the benefits that circumnavigate this transformation, the balance of the $7.6 \%$ remained neutral in their response to this question.

- A collective $47.6 \%$ have agreed that all queries and complaints are resolved within an amicable time period, thereby leaving a contrasting $35.2 \%$ that remained neutral in their response and a further $17.1 \%$ that disagreed in their response to this question.

Results of the primary research data reveal that respondents have echoed their sentiments towards recommended factors that they deemed appropriate to effectively expedite the deployment of factors that will influence the successful implementation of TQM at eFleet.

\subsection{Conclusion to the Findings of the Study}

To determine the extent to which the aim of the research objectives have been fulfilled. The findings of the primary research are illustrated as per each research objective below;

\subsection{Conclusion on Findings from the Demographic Profile of Respondents}

Conclusive findings from the results of the primary research indicate that the demographic profile of respondents illustrate that $67.6 \%$ of the participants are above the age of 33 years which indicates a level of maturity, experience and understanding. This level of maturity will facilitate for the mentoring and grooming of fellow role players including that of all new entrants into eFleet. 
Further findings indicate that the predominant gender facilitated during this research has been female at $55.2 \%$ and male at $44.8 \%$, here as well it has been generally acknowledged and noted that the female gender is by far the more mature of the two which also facilitates the mentoring process (Bergland, 2013:01).

The results of the analysis pertaining to that of academic / tertiary qualifications illustrated that majority of the respondents at $71.4 \%$ have academic or tertiary qualifications against his or her name. This majority assists in deploying the strategies to lateral interventions with knowledge being the strength within the organisation. This further assists in assuring that much more informative decisions are aligned to the goals of the organisation as a strategic measure.

The final findings of the demographic analysis illustrate the years of service at eFleet with a collective $39 \%$ that have been with the organisation for less than 5 years and $25.7 \%$ that have been with eFleet for between 6 to 10 years and a further collective $35.3 \%$ that have been with eFleet for greater than 10 years. The results are indicative of the facts that majority of the respondents have been with the organisation for greater than 5 years serves as a strength to the organisation that will assist in a constantly changing business environment and demand markets.

The collaboration of these results indicates that the respondents serve as assets to the organisation with knowledge being their strength including maturity at age value.

\subsection{Objective 1: To Identify the Challenges that Affect Operational Performance at eFleet}

The findings of the primary research data illustrate that off the eight focal areas that have been tested, there have been moderate challenges to note. Knowledge management pertaining to the industry in focus illustrates that the upkeep of skills and market demand strategies are to be educated to all role players within the organisation. It is also noted that the average 50\% response is aligned to the limited industry knowledge that the respondents possess, thus the average level of accuracy and efficiency. Further findings extrapolated indicate that strategic focus be placed upon language barriers and an ongoing skills and training programme for the upkeep of all staff at eFleet. The analyses of the results are indicative of the moderate responses received to all focally tested areas.

Further analytical intervention highlights that communication has been below average due to language barriers between participants of the various ethnicities, subsequently altering the moderate service offerings to that of all key role players both horizontally and vertically.

The study further revealed that top management interventions as well as the correlated human resource practices have been maintained at an average level. This level of intervention and exposure needs to be escalated in order to meet the ever changing market demands and transformation strategies that have been doing their rounds.

Conclusive to objective one, it needs to be noted that majority of the focal points have been scored within the average percentages indicating that eFleet has the primary requirements for TQM implementation in order to improve operational performance. Contrary to the previous statement it has to be noted that further interventions and acknowledgements be initiated with regards to language barriers to facilitate for effective communication and also to improve the skills and training programmes on an on-going basis with all staff.

\subsection{Objective 2: To Identify the Factors that Hinders the Successful Implementation of TQM at eFleet}

The study indicates that there have been ten focal areas that have been tested with regards to objective two. The findings of an in depth analysis has summed the following conclusion.

It is evident that the leadership factor is evident throughout the organisation with pivotal focus on ensuring the smooth roll out plan regarding the implementation of the TQM system; however eFleet would need to take strides and advances in aligning their critical success factors to the TQM implementation. Special emphasis and uninterrupted focus needs to be expedited to ensure, effective communication which is key to the overall success of the TQM project. It has to be noted that there is an overwhelming level of confidence with regards to the organisation facilitating their own test measures and benchmarks. Further extrapolation has indicated that there has been a moderate above average influence on employee empowerment which has been further influenced by the remarkable 
majority that have agreed that training and education will add wisdom and knowledgeable to the asset base of the organisation.

The focus on customer relationship management and supplier relationship management has been highlighted in order to mitigate inbound and outbound operational risks. Majority of the respondents have also indicated that adopting change and effective communication will further enhance the TQM implementation process. It is the lack of communication and knowledge asset base that has been highlighted with regards to responses been facilitated within an amicable time period.

Conclusively education and training, effective communication and acceptance to change, have been the primary areas that have been highlighted under objective 2 , with special recommendations that have been provided for pertaining to objective 3 and will be elaborated upon, further under recommendations.

\section{RECOMMENDATIONS}

The follow recommendations have been highlighted.

\section{Effective Communication}

Communication is the primary ingredient to any success story. It is highly recommended that communication is effective both upstream and downstream in an organisation. It is the responsibility of senior management to ensure that all correspondence is affected to all employees through a communicable median that is accessible to all. Communication can either be verbal or literal in that there is no fixed median that limits the scope of communication. Management should also adopt the open door policy and staff on the ground have first-hand knowledge with regards to operational processes, procedures and knowledge and the ways in which they can be streamlined. This open door policy of communication can sustain competitive advancements and the attainment of greater market share. Effective communication equals brainstorming which will predominantly cater for strategic business making decisions. eFleet needs to improve and ensure that communication is effective to all staff.

\section{On-Going Training and Education}

Training and education on an on-going basis is the way organisations increase business and operational knowledge thereby creating an advanced knowledge database that would serve as the greatest asset in any organisation. On-going training and education assists all to keep with the times of the ever changing business environment and to remain firm in the competitive markets. Change strategies needs to be educated to all role players. eFleet needs to understand that training and education is pivotal to the sustenance of any organisation in today's ever changing business arena.

\section{Improve Supplier Relationship Management (SRM)}

This is a key area in any business in that a great relationship with suppliers will ensure that the following process (input to output) will be ripple free and facilitated within amicable time periods thereby expediting greater customer satisfaction. By creating this relation with suppliers it is acknowledged that they learn to better understand your needs and to ensure that their offering in terms of service or product is logistically aligned to your exact requirements. This is a key focus area for eFleet as their supplier base is vast and demanding in order to meet the needs and expectations of their customers.

\section{Improve Customer Relationship Management (CRM)}

Organisations that foster effective customer relationship management have an indebted reward of appreciation to the customers as they are the reasons behind the organisations existence. The strength that is affiliated to customer relationships will further enhance customer retention not limited to word of mouth marketing from customers to further prospective customers. The fundamental key to this relationship is to ensure that total customer satisfaction is attained at any given time of operations. eFleet needs to enhance the customer relationship skills in order to sustain competence in their respective market arena.

\section{Change Management Strategies to Overcome Resistance to Change}

Change management is the topic of conversation correlated to our rapid changing markets. The hardest part in any organisation is trying to get staff to mitigate traditional methods and to get them to 
align their thoughts, functions and process to the evolution of business. Once businesses achieve acceptance and buy in from staff on this level the rest of the change would be facilitated in phases. Adoption, acceptance and adherence from all would ensure that initiatives and projects such as TQM and related business enhancements would be implemented with ease and minimal if not no resistance. If the staff at eFleet can adopt the advances of TQM, the implementation process would be a success.

\section{Implement and Install User Friendly Systems}

User friendly systems would ensure that all staff are kept up to speed with regards to their required inputs in the respective fields and the deduced data extracts that they would need to envisage. This also falls under the scope of education and training at eFleet.

\section{Support of Top Management}

This is a pivotal focus area for any organisation as all instructions and delegations are processed and filtered from the top down. Management needs to make their visibility known in all processes and areas of operation thereby encouraging sub-ordinates to work towards a common vision that is aligned to the organisations goal. The top management at eFleet needs to ensure visibility and support laterally through the organisation.

\section{Continuous Improvement}

This is without a doubt an area of focus that needs no introduction as this is the strategy that would assist organisations to keep abreast of the change interventions in the market arena and to continuously strive to give of their best. Continuous improvement facilitates for best practices and this area alone can create great competition in the market arena. eFleet has to ensure that this area of their core operation and related departments are kept up to speed with the external influences.

\section{Further Research}

Further areas that could be explored could be the inception of an appropriate total quality management standard that is relevant to the organisations output. Such standards are adjudicated by the law of the land and would suffice as a tool to achieve competitive advantage if not market leverage.

\section{Conclusion to The Study}

Despite the fact the TQM is a management tool that assists organisations to achieve competitive advantage and greater market share, it is also the way the new millennium facilitates present day business in the vicious market arena. It has to further be noted that despite this fact there are still numerous businesses that still encounter difficulties in implementing this initiative largely due to the fact that many are not ready to adopt the change or if they are ready then they have to deal with the change management issue from the internal candidates. The study has successfully concluded in identifying how TQM can improve operational performance at eFleet a Fleet Management Company within a government organisation. The study was limited to eFleet and its stakeholders and all findings of the analysis have been successfully concluded together with respective correlated recommendations on ways that can instil value to this initiative. The recommendations included have been solely intended for the purpose of eFleet and its initiative to implement a total quality management system to improve operational efficiency. The important key note areas for the focus of TQM have been highlighted under the recommendations and this will serve as a contribution towards the successful implementation process.

The prevalence and nuances of TQM implementation provide much scope for further research. The facilitation of such a study should be extended to larger public and private corporates. This would prove priceless due to the global and local business transformation that has been doing their rounds in the recent past. It has to be noted that the results, analysis, findings, conclusions and recommendations of this study is limited to the study itself and cannot be generalised upon and neither can it be used as a means of remedy to any other organisation, whatsoever. Consequently and correlated to the responses of the study it has to be noted that this study has pivotally aligned a critical need for training and re-training of TQM and to ensure that standards are always elevated if not met taking into consideration the vast evolving markets. This ultimately alludes to the requirement of quality management standards as a primary organisational requirement. 


\section{ACKNOWLEDGEMENTS}

I wish to express and convey my sincere appreciation and gratitude to the following individuals without whose assistance, patience and encouragement, this dissertation would not have been possible. This accolade and achievement is a big thank you to you all.

First and foremost I would like to thank God Almighty above for the blessings and the opportunity to complete this journey (research) and for filling my life with the most incredible people ever.

Sincere thanks to my loving parents Mr Ramsarup Juganath and Mrs Tharamathi Ramsarup. Mum your endless blessings and sacrifices have made this dissertation possible for me to achieve. Dad this achievement is a special thanks to you for always encouraging me and guiding me to excel, thank you mum and dad.

To my immediate family, my brother, sisters, nieces, nephew, nephew in law, brother in law and sister in law, thank you guys for all your support and encouragement.

No amount of praise or words of appreciation will do justice to the depth and extent of gratitude I extend to my supervisor, Mrs Nellie Naranjee, a blessing in a million ways. Your patience, kindness, enthusiasm, motivation and guidance is sincerely appreciated.

To my team of fellow MBA students who undertook this journey with me, your praises, encouragement, laughter, dedication and support has made this achievement possible and will forever be treasured, thank you guys.

Lastly, thank you to all my friends and family for supporting me through this journey.

\section{BIBLIOGRAPHY}

[1] Heizer, J. and Render, B. (2011) Principles of operations management. $10^{\text {th }}$ edition. New Jersey: Prentice Hall.

[2] Singh, V., Grover, S. and Kumar, A. (2008) Evaluation of quality in an educational institute: a quality function deployment approach. Total Quality Management, [Online], Available from: http://www.academicjournals.org. [Accessed 06 February 2015], 3(4), pp.162-168.

[3] Saltsgiver, S. (2004) Accuracy of data in fleet management [Online]. Available from: http://www.automotive-fleet.com [Accessed $5^{\text {th }}$ December 2014].

[4] Zink, K.J. (2007) From total quality management to corporate sustainability based on a stakeholder management. Journal of Management History, 13 (4), pp. 394-401.

[5] Dahlgaard, J.J. and Dahlgaard-Park, S.M. (2006) Lean production, six sigma quality, TQM and company culture. The TQM Magazine Journal, 18, pp. 263-281.

[6] Thamizhmanii, S. and Hasan, S. (2010) A review on an employee empowerment in TQM practice. Journal of Achievements in Material and Manufacturing Engineering, 39 (3), pp. 204210.

[7] Tasar, H.H. and Celik, M. (2011) Examination of implementation level of the total quality management principles by the principals and teachers functioning at elementary schools: The case of adiyaman province. Journal of Asian Social Science, 7 (9), pp. 33-42.

[8] Schiele, H., Calvi, R. and Gibbert, M. (2012) Customer attractiveness, supplier satisfaction and preferred customer status: Introduction, definitions and an overarching framework. Journal of Industrial Marketing Management, 41 (8), pp. 1178-1185.

[9] Gul, A., Jafery, S.A.S., Rafiq, J. and Naeem, H. (2012) Improving employee performance through Total Quality Management. International Journal of Economics and Management Sciences, 1 (8), pp. 19-24.

[10] Parumasur, S.B. and Govender, P. (2009) Managerial competencies as critical ingredients for a total quality management initiative: Perceptions of managers in Kwa-Zulu- Natal public sector division. South African Journal of Industrial Psychology, 35 (1), pp. 01-21.

[11] Charantimath, P.M. (2011). Total Quality Management. India: Pearson

[12] Talib. F., Rahman. Z. and Qureshi, M.N. (2011) Analysis of interaction among the barriers to total quality management implementation using interpretive structural modelling approach. Benchmarking: An International Journal, 18 (4), pp. 563-587. 
[13] Oruma, B.W., Mironga, J.M. and Muma, B.O. (2014) Top management commitment towards implementation of total quality management (TQM) in construction companies in Nakuru County-Kenya. International Journal of Economics, Finance and Management Sciences, 2 (6), pp. 332-338.

[14] Long, C,S. (2013) Success factors for TQM implementation. Pivotal success factors during the TQM implementation process [Online]. Available from: http://www.lifesciencesite.com. [Accessed 10 ${ }^{\text {th }}$ December 2014].

[15] Mckinnon, R,C. (2013) Changing the workplace safety culture. New York: CRC Press.

[16] Wankhade, L and Dabade, B. (2010) Contribution to management science, quality uncertainty and perception, information asymmetry and management of quality uncertainty and quality of perception. London: A Springer Company.

[17] Brown, D. R. (2011) An experiential approach to organisational development. $8^{\text {th }}$ Edition. New Jersey: Pearson.

[18] Grinnell, R.M. Jr., Krysik, J.L. and Unran, Y.A. (2005) Social work research and evaluation: Quantitative and qualitative approaches. $7^{\text {th }}$ edition. Oxford, England: Oxford University.

[19] Saunders, M., Lewis, P. and Thornhill, A. (2007) Research methods for business students. $4^{\text {th }}$ Edition. Harlow, England: Prentice Hall.

[20] Williams, J. (2011) Research philosophy. [Online]. Available from: http:// www.howtodo.d issertationhelpservice.com [Accessed 21 March 2015].

[21] Saunders, M., Lewis, P. and Thornhill, A. (2009) Research methods for business students. $5^{\text {th }}$ Edition. Harlow, England: Prentice Hall.

[22] Rubin,A., and Babbie, E.R. (2009) Essential research methods for social work. $2^{\text {nd }}$ Edition. USA: Cengage Learning.

[23] Sekaran, D.N. (2003) Research methods for business. a skill building approach. $4^{\text {th }}$ Edition. New York: John Wiley \& Sons Inc.

[24] Siegel, A.F. (2011) Practical business statistics. $6^{\text {th }}$ Edition. United Kingdom: Academic Press.

[25] Rubin, A. and Babbie, E.R. (2011) Research methods for social work. $7^{\text {th }}$ Editon. USA: Brooks Cole Cengage Learning.

[26] Althanasiou, T., Debas, H. and Darzi, A. (2010) Key topics in surgical research and methodology. Berlin Heidelberg: Springer Verlag.

[27] Brink, H., Van Der Walt, C. and Van Rensburg, G. (2006) Fundamentals of research methodology for healthcare professionals. Cape Town: Juta and Co (Pty) Ltd.

[28] Wang, H.F. (2009) Intelligent data analysis: Developing new methodologies through pattern discovery and recovery. Hershey: PA Information Science Reference.

[29] Moule, P. and Goodman, M. (2009). Nursing research: an introduction. London: Sage Publications Ltd.

[30] Brutus, S., Aguinis, H. and Wassmer, U. (2013) Self-reported limitations and future directions in scholarly reports: Analysis and Recommendations. Journal of Management, 39 (1), pp. 48-75.

[31] Pannucci, C.J. and Wilkins, E.G. (2010) Identifying and avoiding bias in research. Journal of Plast Reconstr Surg, 126 (2), pp. 619-625.

[32] Blumberg, B., Cooper, D.R. and Schindler, P.S. (2005) Business research methods. London: McGraw-Hill.

[33] Watson, R., McKenna, H., Cowman, S. and Keady, J. (2008) Nursing research design and methods. Elsevier: Elsevier Health Sciences.

[34] Gharakhani, D., Rahmati, H., Farrokhi, M.R. and Farahmandian, A. (2013) Total quality management and organisational performance. American Journal of Industrial Engineering, 1 (3), pp. 46-50.

[35] Oakland, J, S. (2012) Statistical process control. $5^{\text {th }}$ Edition, England: Butterworth-Heinerman

[36] Yang, C.C. (2003) Six sigma and total quality management

[37] Tanninena, K., Puumalainen, K. and Sandstrom, J. (2010) The power of TQM: Analysis of its effects on profitability, productivity and customer satisfaction. Total Quality Management Journal, 21 (1), pp. 171-184. 
[38] Manjunath, U., Metri, B.A. and Ramachandran, S. (2007) Quality management in a healthcare organisation: A case of South Indian hospital. The TQM Magazine Journal, 19 (1), pp. 129-139.

[39] Al-Shobaki, S.D., Fouad, R.H. and Al-Bashir, A.A. (2010) The implementation of Total Quality Management (TQM) for the banking sector in Jordan. Jordan Journal of Mechanical and Industrial Engineering, 4 (1), pp. 304-313.

[40] Irfan, S.M. and Kee, D.M.H. (2013) Critical success factors of TQM and its impact on increased service quality: A case from service sector Pakistan. Middle-East Journal of Scientific Research, 15 (1), pp. 61-74.

[41] Rezaei, A.R., Celik, T. and Baalousha, Y. (2011) Performance measurement in a quality management system. Scientia Iranica Journal, 18 (3), pp. 742-752.

[42] Koh, S., Demirbag, M., Bayraktar, E., Tatoglu, E. and Zaim, S. (2007) The impact of supply chain management practices of performance of SMEs. Industrial Management and Data Systems Journal, 107 (1), pp. 103-124.

[43] Talib, F. (2013) An overview of total quality management: Understanding the fundamentals in a service organisation. International Journal of Advanced Quality Management, 1 (1), pp. 1-20.

[44] Bergland, C. (2013) Females mature faster than males. scientists identify why girls often mature faster than boys. [Online]. Available from https://www.psychologytoday.com [Accessed $29^{\text {th }}$ June 2015]. 